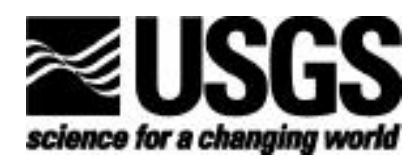

USGS Activity B6

\title{
Hurricane Mitch: Landscape Analysis of Damaged Forest Resources of the Bay Islands and Caribbean Coast of Honduras
}

By Thomas W. Doyle, Thomas C. Michot, Fred Roetker, Jason Sullivan, Marcus Melder, Benjamin Handley and Jeff Balmat

USGS Open File Report OFR 03-175

U.S. Department of the Interior U.S. Geological Survey 
This report is preliminary and has not been reviewed for conformity with U.S. Geological Survey editorial standards.

Any use of trade, product, or firm names is for descriptive purposes only and does not imply endorsement by the U.S. Government.

Suggested citation:

2002, Thomas W. Doyle, Thomas C. Michot, Fred Roetker, Jason Sullivan, Marcus Melder, Benjamin Handley and Jeff Balmat Hurricane Mitch: Landscape Analysis of Damaged Forest Resources of the Bay Islands and Caribbean Coast of Honduras: USGS Open File Report 03-175, xx p. 


\section{List of Tables}

Table 1. Forest damage classification scheme based on percent canopy displacement.

Table 2. Predicted hours of sustained winds by storm category based on the Saffir-Simpson index for areas hardest hit on the mainland, Roatan, and Guanaja including maximum windspeeds.

\section{List of Figures}

Figure 1. Flight lines and video coverage taken over the coastal zone of the Bay Islands and Caribbean coast of northern Honduras for this study.

Figure 2. Composite map of maximum predicted windspeeds by grid location and hurricane tracking across the northern coast extracted from the HURASIM hurricane simulator.

Figure 3. Ground photos of Guanaja forest landscape of pine, hardwood, and mangrove sites impacted by Hurricane Mitch in late fall 1998.

Figure 4. Map of northern Guanaja displaying coastal reaches and flightlines where forest damage was detected and graded by severity indicated by increasing color intensity. Arrows indicate general direction of treefall azimuths observed along this coastal stretch.

Figure 5. Sample freeze frame photo of groundview with histograms of area damage impact, tree heights, and windfall angles for a series of consecutive frames from overflight video of Mangrove Bight area, Guanaja. Shaded area of polar chart of windfall azimuths represents predicted hurricane wind vector range of winds greater than $100 \mathrm{mph}$.

Figure 6. Sample freeze frame photo of groundview with histograms of area damage impact, tree heights, and windfall angles for a series of consecutive frames from overflight video of eastern Roatan area. Shaded area of polar chart of windfall azimuths represents predicted hurricane wind vector range of winds greater than $100 \mathrm{mph}$.

Figure 7. Map illustration of flight line and sites (colored circles) where damage was detectable in lowland and mangrove forest types east of Trujillo along the Caribbean coast of northern Honduras. The degree of canopy disturbance and forest recovery is graded accordingly by color intensity (dark red $=$ severe impact, pink $=$ intermediate, white $=$ low impact). Arrows indicate general direction of treefall azimuths observed along this coastal stretch.

Figure 8. Sample freeze frame photo of groundview with histograms of area damage impact, tree heights, and windfall angles for a series of consecutive frames from overflight video of mainland coast area east of Trujillo, Honduras. Shaded area of polar chart of windfall azimuths represents predicted hurricane wind vector range of winds greater than $100 \mathrm{mph}$. 


\section{Background}

The advent of analog and digital video has provided amateur photographers with professional-like technology to capture dynamic images with ease and clarity. Videography is also rapidly changing traditional business and scientific applications. In the natural sciences, camcorders are being used largely to record timely observations of plant and animal behavior or consequence of some catastrophic event. Spectacular video of dynamic events such as hurricanes, volcanic eruptions and wildfire document the active process and aftermath. Scientists can analyze video images to quantify aspects of a given event, behavior, or response, temporally and spatially. In this study we demonstrate the simple use of an aerial application of videography to record the spatial extent and damage expression of mangrove forest in the Bay Islands and mainland coast of northern Honduras from wind damage following Hurricane Mitch (1998).

The use of aerial photogammetry in forestry applications is not new. Aerial videography using off-the-shelf camcorders, however, has recently evolved with the advent of video technology and is becoming an increasingly popular medium for its low-tech costs and high-tech results. Advantages of camcorder videography include product availability, low cost, instant high-quality imaging, no film processing, and simultaneous audio recording. The other major benefit to modern video camera technology includes the prospect of immediate image capture for digital analysis and reproduction.

Thomasson et. al. (1988, 1994) have demonstrated the uses of multispectral, multitemporal aerial videography for identifying individual trees and species in a bottomland hardwood forest in south Louisiana. Their work showed that large-scale videography can be used to efficiently inventory forest resources at the species and tree level. Kelly (1993) reported on the use of aerial videography to record forest damage and impact of Hurricane Andrew (1992) in the lower Atchafalya Basin in south Louisiana. Results showed the extent of forest destruction by damage class in relation to the hurricane path. Doyle et al. (1994) used videography to examine patterns of windfall and deforestration of mangrove forest across Everglades National Park intersected by Hurricane Andrew (1992). Numerous ground studies in mangrove habitats disturbed by hurricanes demonstrate their susceptibility to windthrow and destruction (Smith et al. 1994, Doyle et al. 1995). These studies demonstrate that low altitude videography is an effective medium and technology for monitoring disturbance impact and forest recovery.

In this study, we conducted a video overflight of coastal forests of the Bay Islands and mainland coast of northern Honduras 14 months after impact by Hurricane Mitch (1998). Coastal areas were identified where damage was evident and described relative to damage extent to forest cover, windfall orientation, and height of downed trees. The variability and spatial extent of impact on coastal forest resources is related to reconstructed wind profiles based on model simulations of Mitch's path, strength, and circulation during landfall. 


\section{Methodology}

\section{Study Area}

Honduras was hit by Hurricane Mitch in November of 1998 with maximum sustained windspeeds of $155 \mathrm{mph}$. The storm slammed the island of Guanaja before turning south and making landfall along the Caribbean coastline of Honduras and then wobbling throughout central Honduras, El Salvador, Guatemala, and Belize at tropical storm strength. Mangrove forests in the coastal zones of the Atlantic and Pacific coasts were severely impacted directly and indirectly by the storm. In this investigation, we aerially surveyed a large-scale region of coastal forest of the Bay Islands and mainland shores of northern Honduras affected by high winds and surge at landfall. Figure 1 illustrates the flight lines and video coverage taken in the coastal zone of northern Honduras for this study.

\section{$\underline{\text { Video Overflight }}$}

Simultaneous oblique and vertical videography was filmed from a Cessna 210 amphibious seaplane along coastal reaches of Guanaja, Roatan, and mainland Honduras. A digital video recorder (Sony DCR-VX1000) was mounted vertically in the fuselage belly with glass window and obliquely from the copilot position. A secondary digital video monitor in the cockpit allowed pilots to observe real-time video exposure and flightline. Flight altitude was predetermined based on lens angle and desired ground resolution to maintain an altitude of 500 feet above sea level and a groundspeed of 70 knots. Onboard global positioning system continuously monitored flight position with video track. Audio transmission was linked between pilot head sets and video recorder. Flight conditions, including altitude, GPS position, speed, and azimuth were reported on a continuous basis onto the video sound track along with other general information about forest condition, degree and direction of downed trees. Ground coverage of image view approximated a 40m x 52m forest patch. Frame size and digital resolution was suitable for identifying single trees and direction of treefall based on root tip-up, stem, and crown position.

\section{Image Analysis}

Post-flight procedures included an on-site validation of image and audio quality. Laboratory evaluation of the videography included a biased sampling of all video frames where residual damage impact was evident. Because ground observations in coastal hardwood forests more than a year after impact showed sufficient recovery, canopy cover in resprouting forests masked the impact of downed stems. Visual analysis involved direct freeze frame evaluation of digital images from damaged areas. Image analysis included image capture by frame set with a graphics board and microcomputer. 
Visual analysis constituted the least technical and efficient means for single frame interpretation. Evaluations included both qualitative and quantitative measures of tree and forest condition. With each freeze frame, we assessed the percent of disturbed or downed canopy cover, percent water coverage, azimuth and length of downed trees. Intermittent audio transmissions were transcribed at or between frame evaluations to obtain explicit flight position, altitude, speed, direction and coincident ground observations. Pre-flight missions were flown over airport runways at Roatan and Guanaja at different altitudes to calibrate frame size and pixel density from known distances of runway width and markings.

A damage classification system was devised to grade impact from low to high on a scale of 0-5 presented in Table 1. Compass direction of downed trees were calculated from flight azimuth. Tree heights were estimated from distance coefficients based on altitude and calibrated ground controls. Ground elevation of this coastal zone is near sea-level for all areas surveyed. Interior transects of Guanaja are evaluated as to damage extent but not at the individual tree level due to unknown topography and climbing flight trajectories of this mountainous island. Non-coastal areas of the mainland are also subject to sloped terrain. Some coastal footage excludes actual forest cover due to coastline circuity and abrupt slopes.

\section{HURASIM: Hurricane Model Predicted Wind Profiles}

HURASIM is a spatial simulation model of hurricane structure and circulation for reconstructing estimated windforce and vectors of past hurricanes. The model uses historic tracking and meteorological data of dated North Atlantic tropical storms from 1886 to 2000. The model generates a matrix of storm characteristics (i.e., quadrant, windspeed, and direction) within discrete spatial units and time intervals specified by the user for any specific storm or set of storms. HURASIM is an empirical model that recreates the spatial structure of past hurricanes based on a tangential wind function, inflow angle offset, forward speed, and radius of maximum winds.

Data input for the model includes tracking information of storm position, latitude and longitude, and maximum sustained wind speed every six hours or less. The model offers a suite of mathematical functions and parameter sets for the tangential wind profile taken from other hurricane studies (Harris 1963, Bretschneiger and Tamaye 1976, Neumann 1987, Kjerfve et al. 1986, Boose et al. 1994). The radius of maximum winds is determined from the reported maximum sustained wind input and a set of empirical equations. HURASIM model output from Hurricane Andrew (1992) was correlated with field data to construct data tables of damage probabilities by site and species and to determine critical windspeeds and vectors of tree mortality and injury (Doyle et al. 1995). HURASIM has also been applied to reconstruct probable windfields of past hurricanes for remote field locations and correlated with tree ring growth patterns and direction of leaning trees and downed logs (Doyle and Gorham 1996). HURASIM has also been used to construct landscape templates of past hurricane activity that are linked with landscape simulation models of coastal habitat (Doyle and Girod 1997). 
Model output is user-specified for given geographic locations assigned by a given point or boundary area. In this study, latitudes and longitudes of select windward and leeward locations about the Bay Islands and mainland were entered to create a log of hurricane activity at 10 minute intervals for predicted winds of hurricane force $(>75 \mathrm{mph}$ ) during Mitch's passage. Results of wind angles, speed, and duration for the different coastlines are correlated with video observations and contrasted between islands and mainland sites.

\section{Results}

Nearly 1000 miles of coastline videography was acquired for this study of which nearly 25 miles is detectibly damaged. Because of the circuity and steepness of some coastal stretches, 40 percent of the video footage is over shallow water rather than terrain. Sites exhibiting residual forest impact more than a year after the hurricane were evident on both Bay islands and the mainland. Severity and extent of impact was greatest on Guanaja and less so on Roatan and mainland coasts. Guanaja endured the highest winds and was the first land mass to encounter and absorb the storm's fury.

Flight conditions provided appropriate scale of forest area and resolution for determining both stand and tree disposition relative to hurricane wind damage. Freeze frame assessments of degree of forest damage were assigned to each locale at the stand level. Tree height profiles were estimated from the videography based on the length of exposed boles in blowdown zones. The high contrast exposure and relatively close groundview made it possible to distinguish the tip-up root base, bole and crown features of fallen trees. It was apparent where trees were snapped from their root base and a true tree height could not be assessed. Individual trees could be readily distinguished even where destruction was almost complete and trees were crisscrossed on one another. Maximum tree lengths were recorded for each plot frame to reconstruct pre-hurricane forest canopy heights.

\section{Hurricane Mitch Simulation}

Figure 2 shows a composite map of maximum predicted windspeeds by grid location across the northern coastal region extracted from the HURASIM hurricane simulator. The map captures Hurricane Mitch's approach on Guanaja before turning southwesterly toward the northern coast of Honduras where it eventually made landfall. Table 2 provides the estimated hours of sustained winds by storm category based on the Saffir-Simpson index for areas hardest hit on the mainland, east Roatan, and east Guanaja. Only Guanaja actually experienced Category 4 level winds at the peak of Hurricane Mitch's development. The hurricane reflected off the steep and mountainous slopes of the northern coast and wobbled about offshore such that it applied hurricane force winds on the Bay Islands on 3 separate passes.

\section{Guanaja: Damaged Forest Resources}


Ground photos taken after the storm showed that all forest types on Guanaja sustained severe impact including mangrove, montane rain forest, and high pine forests (Figure 3). All trees were at a minimum stripped of all leaf cover. Maximum windspeeds approached $160 \mathrm{mph}$ capable of snapping and downing mature trees of all species. Video analysis shows that only mangrove and highland pine forests are slow to recover and show residual damage. Recovery of montane hardwood forests was sufficient to mask any detection of storm impact from aerial view a year later. The lack of sprouting capacity in pine and some mangrove species may explain the contrast in potential recovery of different forest types. Damaged mangrove forests are either blowdowns or fractured snags that have yet to show signs of eventual recovery.

Figure 4 highlights flightlines and coastal reaches where residual forest damage was evident as well as the degree of forest canopy destruction observed from video analysis of Guanaja. Mangrove Bight on the northeastern tip of the island is the largest extent of mangrove forest exhibiting large blowdown patches. Figure 5 illustrates a sample freeze frame and histograms of damage impact for a series of consecutive frames from overflight video of Mangrove Bight area. Results show that nearly all frame images show complete destruction and canopy removal. Most mangrove trees appear to have succumbed to windthrow as tip-ups rather than from snapped trunks. The relatively few standing trees are either low in stature, topped-out, or fractured internally but nonetheless functionally dead. Tree height reconstructions indicate that forests in this area ranged in stature from $7-15 \mathrm{~m}$ in height with an average height of $11.2 \mathrm{~m}$. Treefall angles were confined to a fairly narrow sector in a southeasterly direction between 90 and 180 degrees. Findings show that this windfall pattern is non-random and corresponds with predicted wind angles for windspeeds of Category 3 strength greater than $111 \mathrm{mph}$.

Residual forest damage was also detectable on windward shores of the west end of Guanaja. Damage assessments were much more variable ranging from partial to nearly complete blowdowns. Mangrove fringe along this coastal front account for most of the observed damage. Most of the northern coastline comprises abrupt terrain that supports lower montane rain forest vegetation that sustained some degree of impact but has recovered sufficiently with regrowth so as to mask aerial detection. Fewer sites were found on the leeward, southern coastline of Guanaja with detectable damage. Much of this coastline is developed or includes low stature mangrove islands and fringe that was either spared impact or rebounded quickly. Rising surge waters can often protect low mangrove cover while buffeting from direct wind. The orographic features of Guanaja sheltered dwellings and forests along the island's south coast from the highest winds. Mangrove stands at Savannah Bight were hardest hit on the south coast subject to funneled winds passing across the island and between mountain peaks. Overflights across the interior slopes of mostly high pine forests showed snapped stems and nearly complete devastation of woody vegetation. The potential for natural recovery of mangrove and high pine forests may be in doubt due to the lack of resprouts and regrowth a year after impact. Artificial regeneration may be required to speed forest recovery and deter soil erosion or compaction that may further inhibit restoration by any means. 


\section{Roatan: Damaged Forest Resources}

Forest damage on Roatan was much more patchy and confined to its eastern end. Roatan's westerly position was sufficiently distant to incur maximum windspeeds of $115 \mathrm{mph}$ or less. Figure 6 shows a damaged area of mangrove along the windward northern coast that sustained wind impact resulting in partial blowdowns. Adjoining mangrove stands show scattered dead and downed trees in an otherwise intact canopy. It is not known whether standing dead trees were sufficiently sheltered by surrounding trees from windthrow but sustained enough wind shaking to sustain fractured stems subject to post-storm dessication. Figure 6 illustrates a series of video frames and analysis of observed damage on Roatan similar to blowdown sites on Guanaja in stature and severity excepting direction of treefall. Where blowdowns on Guanaja were more easterly, blowdown sites on Roatan were more southerly. Peak winds capable of topping mangroves struck earlier on Guanaja than on Roatan which accounts for the relative offset in windthrow azimuth. These results also indicate that absolute windspeed approaching critical levels corresponds more closely with damage expression than did wind duration.

\section{Caribbean Coast: Damaged Forest Resources}

The extent and degree of forest damage along the mainland coast of northern Honduras could be attributed to direct windfall and in some cases to downstream flooding in floodplain areas of intersecting rivers. Most of the coastline is either in crop production or other cultured types which limited comparisons within and across the region. Mangrove stands along the coastline sustained significant losses south of Trujillo where the hurricane made landfall. Figure 7 shows a distribution of sites where damage was detectable in lowland and mangrove forest types. Windspeeds were similar to Roatan lacking any winds above $131 \mathrm{mph}$. Where damage was detectable, it compared similarly to Roatan and Guanaja resulting in partial blowdowns in coastal reaches struck with Category 3 winds and patchy elsewhere. Like Guanaja, forests on the steep terrain, mostly high pine forests, were snapped and felled in easterly directions as a direct result of high winds. Mangrove stands along the coastline sustained significant losses south of Trujillo where the hurricane made landfall. Figure 8 shows a representative video image and analysis of damage to lowland hardwood forest or mangrove along the mainland coast. Despite filming a lengthy section of mainland coast, damage was either fairly minimal or confined to the coast. The stature of damaged lowland hardwood and mangrove forest in this coastal reach ranges from $7-17 \mathrm{~m}$ in height. Treefall orientation is more easterly than observed at Roatan or Guanaja. In all cases, treefall azimuths correlate well with predicted storm behavior where winds exceed $111 \mathrm{mph}$.

\section{Conclusion}


Videography is an effective tool for cataloging forest damage caused by wide area impacts of large scale disturbances such as hurricanes. Where ground accessibility is hampered by damage to social infrastructure and downed trees following hurricane disasters, aerial observations are an efficient and comprehensive means to achieve regional assessments. Despite logistical delays and priorities, aerial videography was obtained a little more than a year after Hurricane Mitch struck Honduras that provided evidence of damage extent and recovery potential.

Landscape analysis of hurricane impact on coastal forest of the Bay Islands and Caribbean coast of northern Honduras demonstrate that lowland mangrove and high pine forest habitats were severely damaged and are slow to recover compared with hardwood forest types. Damage assessments from the study are considered conservative estimates given that regrowth may be masking downed trees and branches. Ground photos of Guanaja habitats and shoreline taken days after the storm more clearly show the extent of stem breakage and foliage reduction that resulted from storm impact. Aerial observations of toppled mangrove and high pine vegetation on the Bay Islands more than a year after the storm show little sprouting of residual stumps and snags or regeneration from new seedlings or surviving saplings.

A hurricane simulation model was used to relate site-specific wind conditions and expression of damage. The degree of hurricane force varied by island and shoreline exposure. Forests on Guanaja were the only sites to endure Category 4 winds above 130mph. Forest blowdowns were evident to a lesser extent on Roatan and mainland sites where predicted winds barely reached minimal Category 3 winds above $111 \mathrm{mph}$. Variability in damage extent increased with decreasing wind conditions dictated by distance from storm path and waning intensity. Treefall orientation directly correlated with predicted wind angles by site distinct for each island and mainland coast where damage was observed. Findings showed that downed tree azimuths correlated with the angle of strongest winds above a critical threshold where stem breakage is exacted, approximating 110mph. These results are consistent with other mangrove forest studies in the Everglades following Hurricane Andrew (1992) (Doyle et al. 1994, 1995).

Coastal terrain and land use affect the distribution of natural vegetation in the Bay Islands and mainland coast that limits aerial assessment of damaged forests. Landcape analysis of videography from this study clearly shows that some areas of the regional coastline have been denuded of vegetative cover related to storm impact. Hardwood habitats demonstrated greater resilience to hurricane force and greater potential to rebound, while mangrove and pine habitat failed to show signs of recovery more than a year after impact. Artificial restoration efforts may be necessary in these habitat types and locations to retain soils from erosional forces and to speed site recovery and function. 


\section{References}

Bretschneider, C. L. and Tamaye, E. E. 1976. Hurricane wind and wave forecasting techniques. In: Proceedings of the 15th Coastal Engineering Conference, held Honolulu, Hawaii, July 11-17, (ASCE), Chapter 13, p. 202-237.

Doyle, T. W., C. J. Wells, K. W. Krauss, and M. Roberts. 1994. The Use of Videography to Analyze the Spatial Impact of Hurricane Andrew on south Florida mangroves. pp. 222-227. IN: Proceedings of GIS/LIS 94 Annual Conference held October 27-30, 1994, Phoenix, AZ. Published by American Congress on Surveying and Mapping, Bethesda, Maryland.

Doyle, T. W., T. J. Smith, and M. B. Robblee. 1995. Wind damage effects of Hurricane Andrew on mangrove communities of southwest Florida. J. of Coastal Research 18: 159-168.

Doyle, T. W. and L. E. Gorham. 1996. Detecting hurricane impact and recovery from tree rings. IN: J. S. Dean, Meko, D. M., and Swetnam, T. W., Tree-Rings, Environment and Humanity, Radiocarbon Press, Tucson, Arizona. Radiocarbon 1996, pp.405-412.

Doyle, T. W. and G. Girod. 1997. The frequency and intensity of Atlantic hurricanes and their influence on the structure of south Florida mangrove communities. Ch. 7. pp. 111-128. IN: H. Diaz and R. Pulwarty (eds.), Hurricanes, Climatic Change and Socioeconomic Impacts: A Current Perspective, Westview Press, New York, N.Y. pp325.

Harris, D. L. 1963. Characteristics of the hurricane storm surge. U. S. Dept. of Commerce, Technical Paper No. 48, Washington, D.C., 138p.

Kjerfve, B., Magill, K. E., Porter, J. W., AND Woodley, J. D. 1986. Hindcasting of hurricane characteristics and observed storm damage on a fringing reef, Jamaica, West Indies. Journal of Marine Research 44:119-148.

Neumann, C. J. 1987. The National Hurricane Center risk analysis program (HURISK). NOAA Technical Memorandum NWS NHC 38, Washington D.C., 56p.

Smith, T.J.III, Robblee, M.B., Wanless, H.R., and Doyle, T.W. 1994. Mangroves, hurricanes, and lightning strikes. Bioscience 44,256-262.

Kelly, J. F. 1993. Hurricane Andrew Forest Damage Assessment. World Resource Review 5: 401-408. 
Thomasson, J. A., M. P. Mailander, F. E. Sistler, M. E. Wright, B. D. Jackson, and C. W. Bennett. 1988. Forest Inventory of the Atchafalaya Basin Using Aerial Videography. Aerican Society of Agricultural Engineers Paper No. 88-3544, 19 p.

Thomasson, J. A., C. W. Bennett, B. D. Jackson, and M.P. Maillander. 1994. Differentiating bottomland tree species with multispectral videography. Photogrammetric Engineering and Remote Sensing 60: 55-59. 